\title{
Coordination polymer nanowires/reduced graphene oxide paper as flexible anode for sodium-ion batteries
}

\author{
Zehang Sun, Ke Tan, Linrui Hou, Yang Liu ${ }^{*}$ and Changzhou Yuan
}

The growing demand for lithium-ion batteries (LIBs) will lead to the shortage and high cost of lithium resource in the foreseeable future. Thus, it is essential to develop alternative battery technologies which are reliable and costeffective [1]. Sodium-ion batteries (SIBs) have been regarded as one of the most promising alternatives for LIBs due to the abundance of sodium [2]. However, the large radius of $\mathrm{Na}^{+}$ion always brings about low kinetics and instability of batteries. Therefore, the major challenge in advancing SIB technology lies in finding suitable host materials for $\mathrm{Na}^{+}$ions, especially high performance anode materials. Until now, the sodium storage capabilities of some inorganic (e.g., metal oxides and sulfides, alloying type metals) and organic (e.g., carboxylates, imides) materials have been tested [3-7]. Although metal-based inorganic electrodes exhibit high capacity in the storage of $\mathrm{Na}^{+}$ions, large volume expansion and severe capacity fading arise during the conversion or alloying reactions [3-5]. Organic electrodes in SIBs mainly based on $\mathrm{C}=\mathrm{O}$, $\mathrm{C}=\mathrm{N}$ bonds and doping reactions provide the possibility for stable accommodation of large $\mathrm{Na}^{+}$ions [6]. Besides, organic electrode materials possess other advantages such as abundance, environmental friendliness, structural diversity and flexibility. However, the inherent poor conductivity and high solubility in non-aqueous electrolytes become the bottlenecks limiting their further developments [7].

Polymerization has been confirmed to be an efficient way to mitigate the solubility of organics in electrolyte. The large extended backbone of repeating units could largely improve the stability of organics. Thus, different kinds of polymers such as conductive polymers (e.g., polypyrrole, polyaniline); carbonyl polymers (e.g., polyimides, polyquinones), radical polymers (e.g., nitroxidebased polymer) and coordination polymers (CPs) (e.g.,
Prussian blue) have been synthesized and tested as cathode or anode materials for SIBs [6-8]. Among them, CPs, especially their porous type namely metal organic frameworks (MOFs), have attracted lots of attention due to their facile synthesis, structural versatility, large surface area and enormous channels [9]. The CPs can be treated as one-, two- or three dimensional (1D, 2D or 3D) networks resulting from the coordination of metal ions and organic ligands [10]. As one important kind of CPs, MOFs always have well defined crystalline and porous structures while CPs may not. The CPs-based materials have been used as electrode materials for SIBs. For example, Prussian blue and its analogues with a general chemical formula of $\mathrm{A}_{x} \mathrm{M}\left[\mathrm{Fe}(\mathrm{CN})_{6}\right]_{y} \cdot z \mathrm{H}_{2} \mathrm{O}$ (A represents alkali metal ion, $\mathrm{M}_{\mathrm{a}}$ and $\mathrm{M}_{\mathrm{b}}$ are transition metal ions) have been treated as one of the most promising SIB cathodes as $\mathrm{Na}^{+}$ions can frequently insert into and desert from their lattices in a relatively high voltage window [11]. The CPs can also store $\mathrm{Na}^{+}$ions in low voltage potentials. For instance, Co- and Cr-based MOFs were synthesized by Dong et al. [12] through the coordination of 5-amino-isophthalic acid with $\mathrm{Co}^{2+}$ and $\mathrm{Cr}^{2+}$ ions, respectively, and tested as anode materials for SIBs. It has been confirmed that the redox reactions were carried out between $\mathrm{Na}^{+}$ions and carboxyl/amine groups; nevertheless, the valences of $\mathrm{Co}^{2+}$ and $\mathrm{Cr}^{2+}$ were not changed during the charge and discharge processes. Recently, Cohexaaminobenzene (Co-HAB) was synthesized by Park et al. [13], which could provide a three-electron redox reaction in a voltage window of $0.5-3.0 \mathrm{~V}$, presenting a new promising anode material for SIBs.

Although, some good results have been achieved, there are still obstacles in designing and constructing CPsbased electrodes. One of the challenges is to improve their electrical conductivity and structural stability during 
electrochemical reactions. Slurry coating method is commonly used in constructing CP electrodes by using the current collector, conductive agent and polymeric binder, resulting in a complicated technology and low energy densities [14-16]. The fabrication of CPs/carbon hybrids is an efficient way to solve these problems because carbonaceous materials (e.g., graphene) can not only act as fast electron transport networks but also provide stable structural protections [17-19]. Moreover, the excellent mechanical properties of graphene make it suitable substrate to construct flexible electrodes. Herein, flexible, interconnected CP nanowires/reduced graphene oxide (CPNWs/rGO) paper was constructed through a facile assembly and reduction process with Fe-based $\mathrm{CP}$ nanowires (Fe-CPNWs) and GO as precursor. The FeCPNWs constructed by $\mathrm{Fe}^{2+}$ (metal ions) and nitrilotriacetic acid (organic ligands) have a high aspect ratio and a large amount of functional groups (e.g., carboxyl), which can not only act as building blocks for freestanding electrodes but also provide enormous active sites for $\mathrm{Na}^{+}$ion storage. The hybrid paper was used as a freestanding electrode for SIBs, showing a relatively high specific capacity, superior rate capability, and stable cycling performance.

As schematically illustrated in Fig. 1, the synthesis of $\mathrm{Fe}-\mathrm{CPNW} / \mathrm{rGO}$ paper is facile with two steps. Firstly, the 1D Fe-CPNWs with $\mathrm{Fe}^{2+}$ ions on the surface are electrostaticly attached to the 2D GO nanosheets containing negatively charged oxygen-containing functional groups, then assembled into paper structure via filtration. Secondly, GO is thermally reduced at a relatively low temperature of $300^{\circ} \mathrm{C}$, which can improve the electrochemical conductivity of GO nanosheets without damaging the crystal structure of Fe-CPNWs.

As shown in Fig. 2a, the free-standing and flexible paper with a diameter of $\sim 4 \mathrm{~cm}$ was obtained after the synthetic procedures. The paper structure exhibits good mechanical deformations such as bending, twisting and folding (Fig. 2a and Fig. S1). Field-emission scanning electron microscopy (FESEM) and transmission electron microscopy (TEM) were used to investigate the morphology and microstructure of the Fe-CPNWs/rGO paper. The cross-section FESEM image (Fig. 2b) exhibits the thickness of paper structure is $\sim 46 \mu \mathrm{m}$. Meanwhile, the top-view image (Fig. 2c) depicts the hybrid paper is constructed by $1 \mathrm{D} \mathrm{Fe}$-CNPWs (with a diameter of $\sim 150 \mathrm{~nm}$ ) and 2D rGO nanosheets with enormous macro-pores. The magnified image (Fig. 2d) exhibits the FeCPNWs are closely attached to the surface of rGO nanosheets, consisting with the TEM image (Fig. 2e). Furthermore, the Fe-CPNWs consist of $\mathrm{C}, \mathrm{N}, \mathrm{O}$ and $\mathrm{Fe}$ elements confirmed by the elemental mapping images (Fig. 2f-i). Noteworthy, there is little morphology change of $\mathrm{Fe}-\mathrm{CPNW}$ before and after the thermal treatment (Fig. S2). As reported, the 1D/2D hybrid structure always endows materials with good mechanical and electrochemical properties due to their synergistic effect $[20,21]$. Moreover, the porous networks can provide enough channels for the soakage of electrolyte and diffusion of $\mathrm{Na}^{+}$ions [22,23]. Thus, outstanding electrochemical performance may be expected.

A series of measurements including thermal gravimetric analysis (TGA), X-ray diffraction (XRD), and Xray photoelectron spectroscopic (XPS) have been taken to investigate the crystal structure and composition of FeCPNWs and their hybrids. As shown in Fig. 3a, the FeCPNWs have a high thermal stability with nearly no weight loss before $300^{\circ} \mathrm{C}$ under $\mathrm{N}_{2}$. Afterwards, there are two drastic weight decrements ranged in $400-458^{\circ} \mathrm{C}$ and $556-600^{\circ} \mathrm{C}$, which can be ascribed to the decomposition of organic ligands and the following carbonization process. The Fe-CPNWs show less thermal stability in $\mathrm{O}_{2}$ atmosphere as the sample begins to be oxidized at a lower temperature of $\sim 200^{\circ} \mathrm{C}$. The final weight loss is $55.6 \mathrm{wt} \%$ due to the oxidation of $\mathrm{Fe}-\mathrm{CPNWs}$ to iron oxide $\left(\mathrm{Fe}_{2} \mathrm{O}_{3}\right)$. It can be inferred that the chemical formula of $\mathrm{Fe}$ -

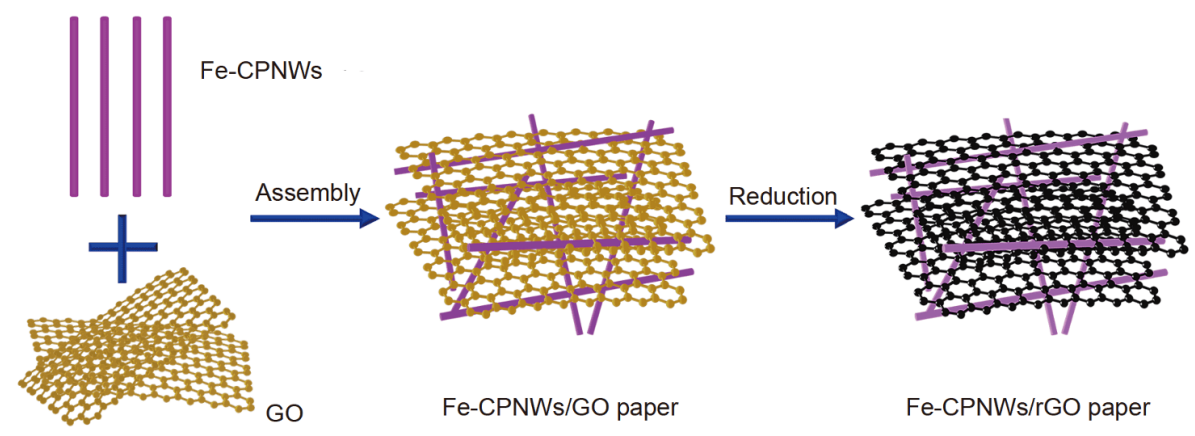

Figure 1 Schematic illustration for the construction of Fe-CPNWs/rGO paper. 


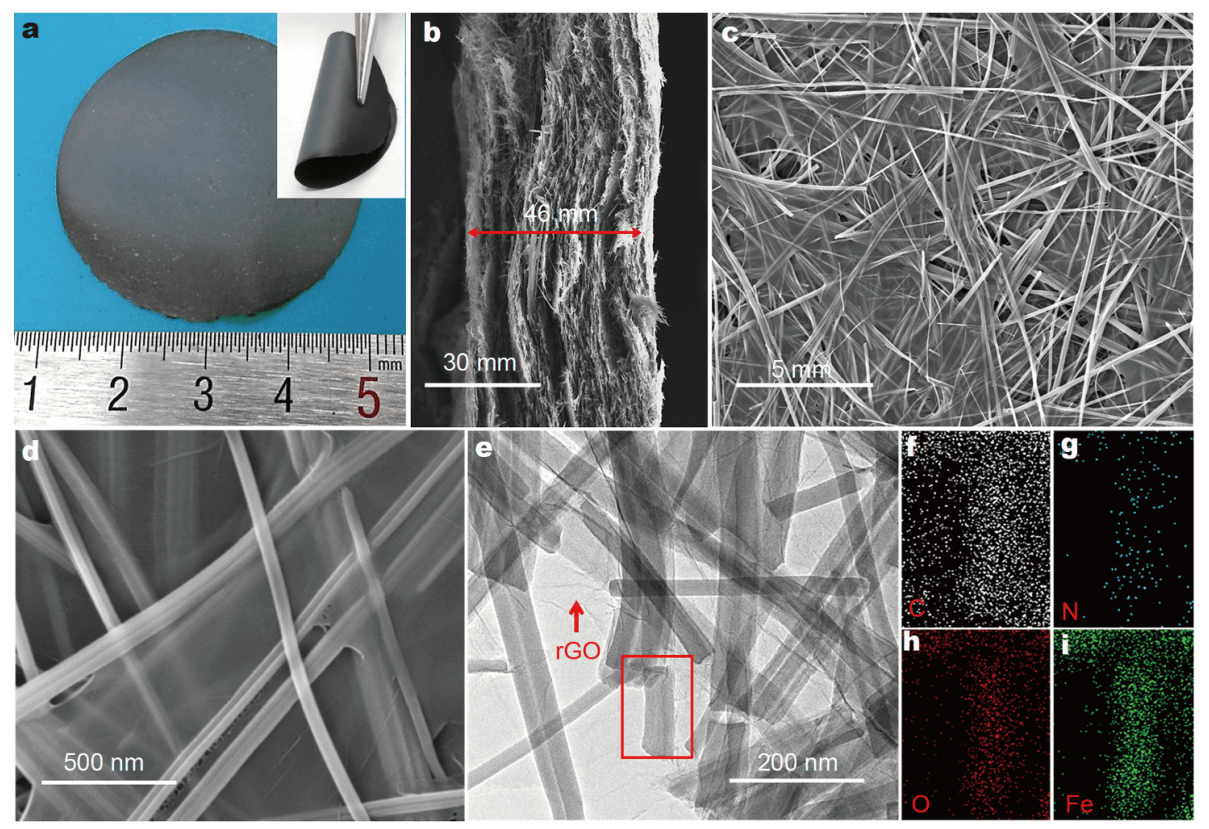

Figure 2 (a) Digital images, (b) cross-section and (c, d) top-view FESEM images, (e) TEM image and (f-i) corresponding elemental mapping images $(\mathrm{C}, \mathrm{N}, \mathrm{O}, \mathrm{Fe}$ ) of the Fe-CPNWs/rGO paper.
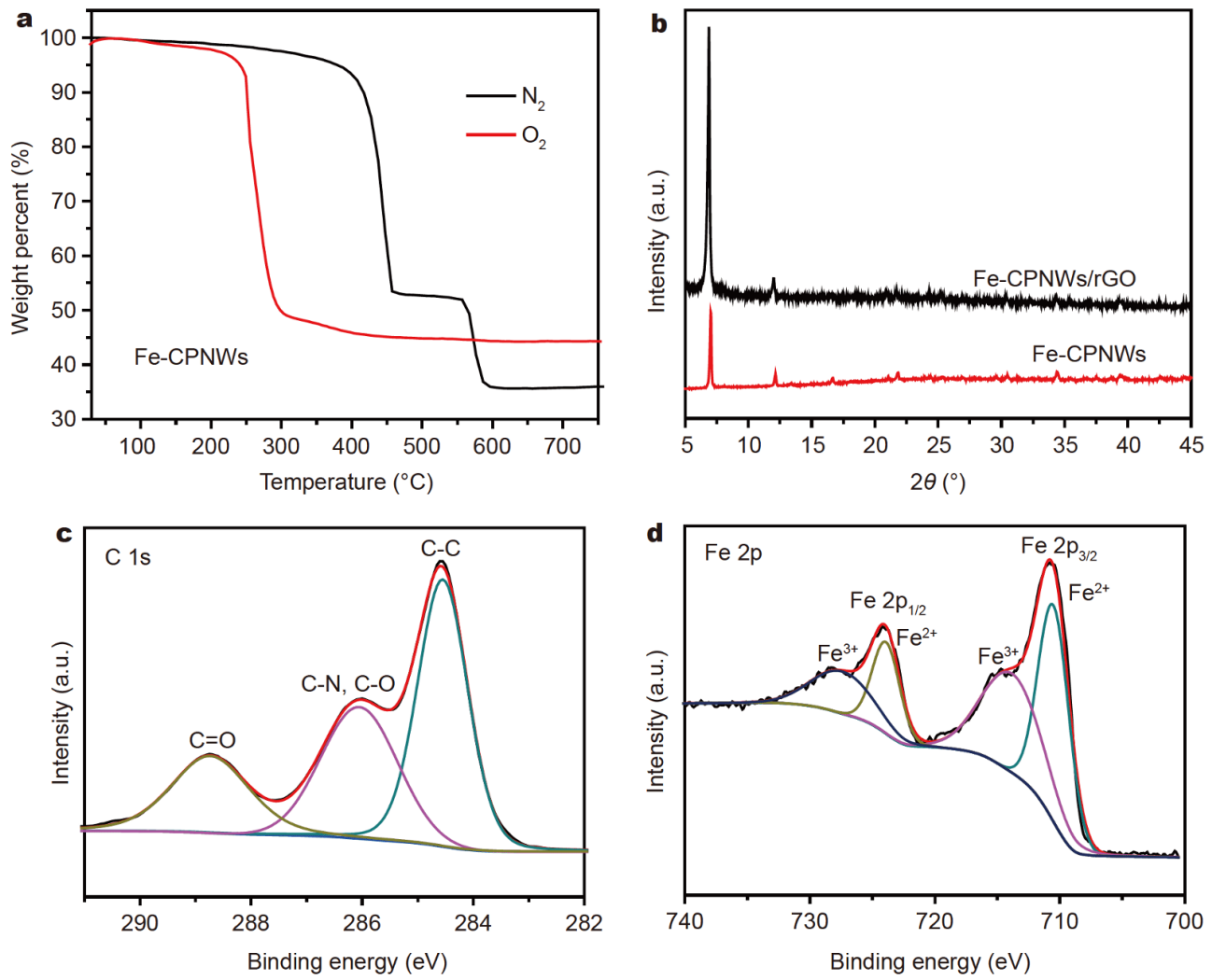

Figure 3 (a) TGA of Fe-CPNWs conducted in $\mathrm{N}_{2}$ and $\mathrm{O}_{2}$ atmospheres, respectively. (b) XRD patterns of pristine Fe-CPNWs and Fe-CNPWs/rGO paper. (c, d) XPS spectra (C 1s and Fe 2p) of the Fe-CPNWs/rGO paper. 
CPNWs is $\mathrm{Fe}_{3}(\mathrm{NA})_{2}$ (NA represents nitrilotriacetic acid) based on the weight loss. According to the results of TGA, a suitable temperature of $300^{\circ} \mathrm{C}$ has been chosen to modestly reduce the functional groups attached on $\mathrm{GO}$, and keep the intact structure of Fe-CPNWs. Fig. 3b shows that all the diffraction peaks of Fe-CPNWs in the hybrid paper are in accordance with the pristine samples, confirming there is no crystal structure change. However, the intensity of peaks becomes stronger, which can be attributed to the crystallization process during the thermal treatment.

XPS were analyzed to find out the surface chemical compositions of Fe-CPNWs/rGO. As shown in all survey spectrum (Fig. S3), there are C, O, N, Fe elements coexisting in the hybrid, which is in accordance with the elemental mapping. The $\mathrm{C} 1 \mathrm{~s}$ spectrum can be de-convoluted into three peaks. The $\mathrm{C}-\mathrm{C}$ peak located at $284.6 \mathrm{eV}$ is assigned to the carbon framework of graphene. The other two peaks at 286.1 and $288.8 \mathrm{eV}$ belong to $\mathrm{C}-\mathrm{N} / \mathrm{C}-\mathrm{O}$ (amine/hydroxyl) and $\mathrm{C}=\mathrm{O}$ (carboxyl and carbonyl) groups, deriving from the organic ligands (NA) and partial reduced graphene oxide nanosheets [24]. The Fe 2 p spectrum (Fig. 3d) displays two couple peaks located at 710.6/724.0 eV and 714.4/727.9 eV, respectively. The former peaks can be attributed to $\mathrm{Fe}^{2+}$ ions coordinated with carboxyl (OCO-Fe) and amine (N-Fe) groups [24,25], while the latter $\mathrm{Fe}^{3+}$ ions come from the oxidation of surface $\mathrm{Fe}^{2+}$ ions due to their less stability in air.

Benefiting from the flexible mechanical property, the $\mathrm{Fe}-\mathrm{CPNW} / \mathrm{rGO}$ paper is directly used as free-standing anode for SIBs. Fig. 4a shows the cyclic voltammetry (CV) curves of the paper electrode tested in a voltage window of $0.01-3.0 \mathrm{~V}$ at a scan rate of $0.1 \mathrm{mV} \mathrm{s}^{-1}$. During the first cathodic scan, the broad reduction peak from 1.6 to $0.9 \mathrm{~V}$ can be ascribed to the organic ligand transformation (i.e., carboxylate to enolate conversion), which becomes stronger in the following cycles due to the activation process [26]. The sharp peak sloping down to $0.01 \mathrm{~V}$ is associated with the formation of solid electrolyte interface (SEI) film and the side reactions between the surface functional groups attached on polymers and $\mathrm{Na}^{+}$ ions [12,27-29]. Two oxidation peaks centered at $1.79 \mathrm{~V}$ can be ascribed to the $\mathrm{Na}^{+}$desertion process. In the subsequent cycles, a new reduction peak at $0.93 \mathrm{~V}$ appears, due to the structure reconstruction in the first cycle. The CV curves are basically overlapped thereafter, indicating a good reversibility. To further investigate the electrochemical mechanism of electrodes, ex-situ XPS analyses of the electrode materials collected at the dis- charge state after 5 cycles were done. As shown in the Fe 2 p spectrum (Fig. S4a), there are only two peaks at 711.0 and $724.6 \mathrm{eV}$, which can be ascribed to the $\mathrm{Fe}^{2+}$ ions [25]. The absence of $\mathrm{Fe}(0)$ indicates the valence of centered metal atoms remains unchanged during the electrochemical reactions. However, the peak intensities and areas of $\mathrm{C}=\mathrm{O}$ and $\mathrm{C}-\mathrm{N} / \mathrm{C}-\mathrm{O}$ groups decrease significantly at the discharge state ( $\mathrm{C} 1 \mathrm{~s}$ spectrum, Fig. $\mathrm{S} 4 \mathrm{~b})$. The above results point out that the organic moieties especially carboxylic groups play an essential role in the reversible redox reactions.

The initial discharge and charge capacities of the FeCPNWs/rGO paper are 787 and $454 \mathrm{~mA} \mathrm{~h} \mathrm{~g}^{-1}$ with a coulombic efficiency (CE) of $57.7 \%$ (Fig. 4b). The irreversible part can be attributed to the formation of SEI film and the side reactions [12,27-29]. The CE reaches over $96 \%$ for the 5 th cycle and can be kept from then on. Fig. $4 \mathrm{c}$ shows the cycling performance of the Fe-CPNWs/ rGO paper at a current density of $100 \mathrm{~mA} \mathrm{~g}^{-1}$. The paper electrode demonstrates a very stable cycling performance as a discharge capacity of $319 \mathrm{~mA} \mathrm{~h} \mathrm{~g}^{-1}$ can still be kept after 200 cycles, which is superior to the Fe-CPNWs paper (7 $\left.\mathrm{mA} \mathrm{h} \mathrm{g}^{-1}\right)$ without rGO addition (Fig. S5a). Evidently, the rGO substrate can not only improve the electrochemical conductivity of the hybrid electrodes (as confirmed by electrochemical impendence spectra, Fig. S6), but also help keep their structures intact (Figs S7 and S8). In addition to good cycling stability, the FeCPNWs/rGO paper also exhibits excellent rate capability, yielding average reversible capacities of 404, 308, 272, 220,148 and $120 \mathrm{~mA} \mathrm{~h} \mathrm{~g}^{-1}$ at the current densities of 100 , $300,500,1000,2000$ and $3000 \mathrm{~mA} \mathrm{~g}^{-1}$, respectively. Meanwhile, the capacity can restore to $340 \mathrm{~mA} \mathrm{~h} \mathrm{~g}^{-1}$ after deep cycling at a high rate. In contrast, the Fe-CPNWs paper without rGO shows inferior rate performance as only $3 \mathrm{~mA} \mathrm{~h} \mathrm{~g}^{-1}$ can be obtained at $500 \mathrm{~mA} \mathrm{~g}^{-1}$ (Fig. S5b). To further confirm the rate capability and cyclic stability, long cycling performances of the Fe-CPNWs/rGO paper electrode under high rates of 500 and $1000 \mathrm{~mA} \mathrm{~g}^{-1}$ were tested (Fig. 4e). The capacity loss at the initial 500 cycles can be ascribed to the formation of unstable SEI layers at a high current density, which slow down the Na-ion transport behavior and degrade the electrochemical performance [16,22]. However, stable SEI layer is formed during the long cycling performance and capacities of 115 and $100 \mathrm{~mA} \mathrm{~h} \mathrm{~g}^{-1}$ can be achieved after 2000 and 4000 cycles with very low capacity decay rates of $0.03 \%$ (at $500 \mathrm{~mA} \mathrm{~g}^{-1}$ ) and $0.02 \%$ (at $1000 \mathrm{~mA} \mathrm{~g}^{-1}$ ) per cycle. The electrochemical performance of the $\mathrm{Fe}-\mathrm{CPNW} / \mathrm{rGO}$ paper is superior to many organic anodes previously re- 

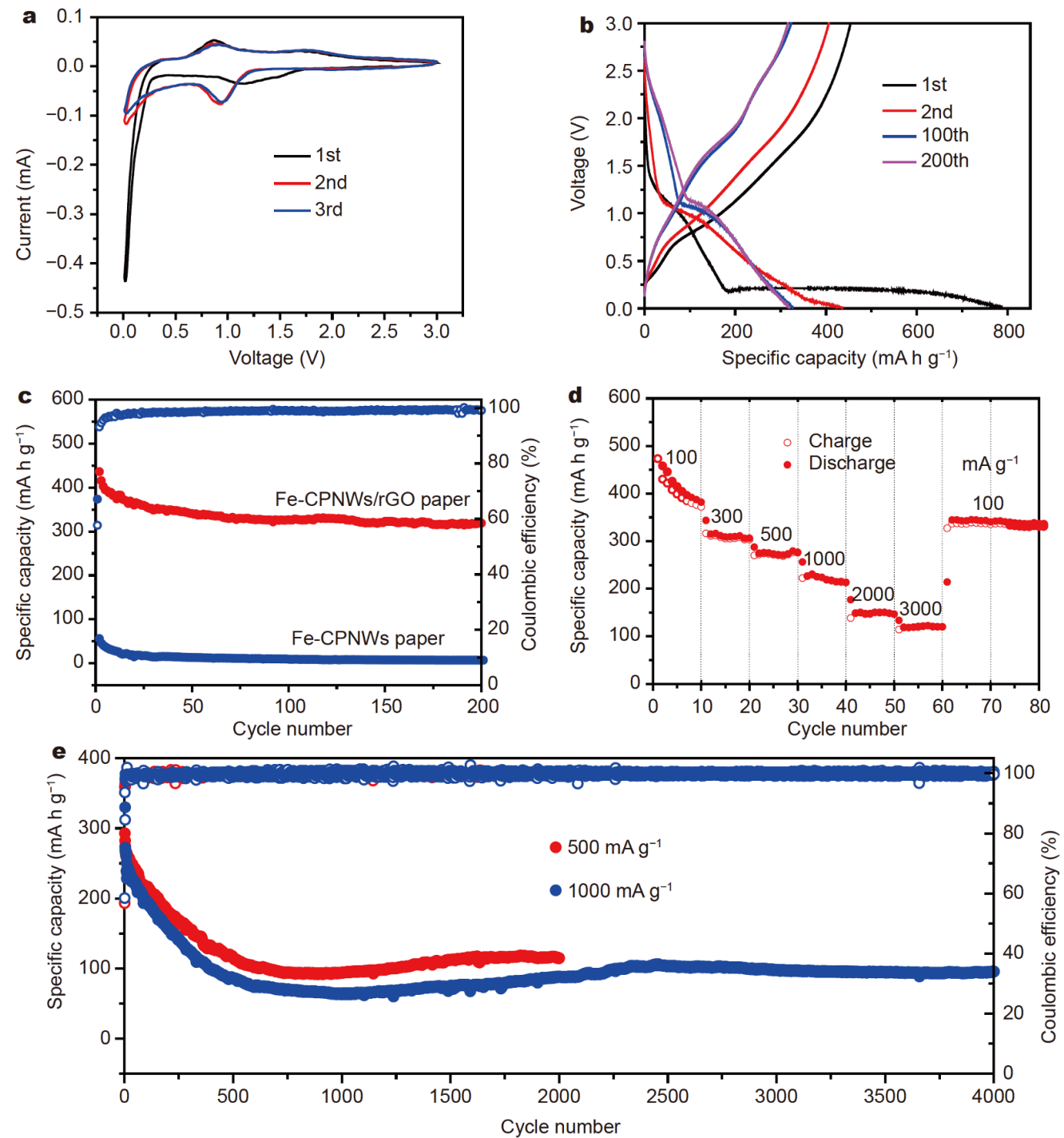

Figure 4 Electrochemical performance of the Fe-CPNWs/rGO paper for SIBs. (a) CV curves $\left(0.1 \mathrm{mV} \mathrm{s}^{-1}\right)$ between 0.01 and $3.0 \mathrm{~V}$. (b) Galvanostatic charge and discharge voltage profiles $\left(100 \mathrm{~mA} \mathrm{~g}^{-1}\right)$. (c) Comparative cycling performance $\left(100 \mathrm{~mA} \mathrm{~g}^{-1}\right)$ of Fe-CPNWs/rGO paper and Fe-CPNWs paper without rGO. (d) Rate capability at various current rates from 100 to $3000 \mathrm{~mA} \mathrm{~g}^{-1}$. (e) Long-term cycling performance at 500 and $1000 \mathrm{~mA} \mathrm{~g}^{-1}$.

ported (Table S1) [12,18,30-34]. In addition, a full sodium ion cell was assembled with $\mathrm{Na}_{3} \mathrm{~V}_{2}\left(\mathrm{PO}_{4}\right)_{3} / \mathrm{rGO}$ $(\mathrm{NVP} / \mathrm{rGO})$ as the cathode and $\mathrm{Fe}-\mathrm{CPNWs} / \mathrm{rGO}$ as the anode. A voltage window of $0.5-3.9 \mathrm{~V}$ has been chosen according to the voltage profiles and corresponding $\mathrm{dQ} /$ $\mathrm{d} V$ curves of NVP/rGO and Fe-CPNWs/rGO (Fig. S9a, b). The full cell delivers a relatively stable cycling performance as a charge capacity of $171 \mathrm{~mA} \mathrm{~h} \mathrm{~g}^{-1}$ can be kept after 100 cycles at $100 \mathrm{~mA} \mathrm{~g}^{-1}$ (Fig. S9c, d). Moreover, a flexible pouch-type SIB was also fabricated and the light emitting diode (LED) can be easily lightened under the normal and bending states (Fig. S10).

In conclusion, CP-based flexible SIB anodes consisting
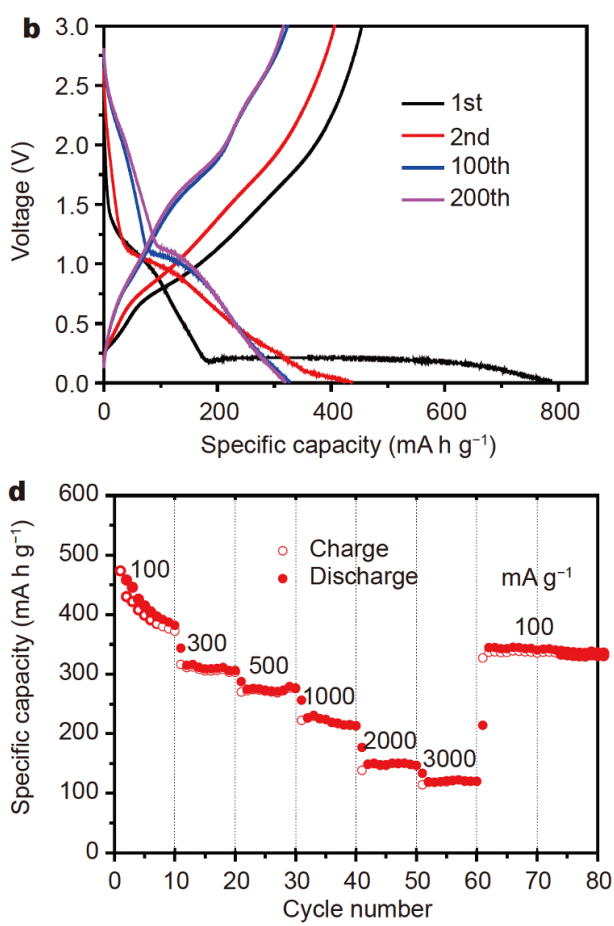

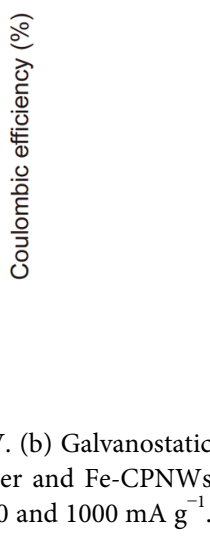

of $1 \mathrm{D} \mathrm{Fe}$-CPNWs and 2D rGO are constructed via the assembly and controlled reduction process. The multidimensional hybrid electrodes exhibit excellent mechanical and electrochemical properties. When tested as freestanding paper anodes for SIBs, the hybrids exhibit high rate capability (404-120 $\mathrm{mA} \mathrm{h} \mathrm{g}^{-1}$ at a current density of $\left.100-3000 \mathrm{~mA} \mathrm{~g}^{-1}\right)$ and long cyclic life $\left(100 \mathrm{~mA} \mathrm{~h} \mathrm{~g}^{-1}\right.$ can be kept after 4000 cycles at $\left.1000 \mathrm{~mA} \mathrm{~g}^{-1}\right)$. The organic moieties (carboxyl and amine groups) are the redox centers in CPs. This work provides a new flexible anode candidate for SIBs.

Received 9 December 2019; accepted 26 December 2019; published online 17 January 2020 
1 Liu Y, Sun Z, Tan K, et al. Recent progress in flexible non-lithium based rechargeable batteries. J Mater Chem A, 2019, 7: 4353-4382

2 Deng J, Luo WB, Chou SL, et al. Sodium-ion batteries: From academic research to practical commercialization. Adv Energy Mater, 2018, 8: 1701428

3 Jin T, Han Q, Wang Y, et al. 1D nanomaterials: Design, synthesis, and applications in sodium-ion batteries. Small, 2018, 14: 1703086

4 Huang ZD, Zhang TT, Lu H, et al. Bimetal-organic-framework derived $\mathrm{CoTiO}_{3}$ mesoporous micro-prisms anode for superior stable power sodium ion batteries. Sci China Mater, 2018, 61: 1057-1066

5 Li D, Zhao X, Yu R, et al. Formation of multi-shelled nickel-based sulfide hollow spheres for rechargeable alkaline batteries. Inorg Chem Front, 2018, 5: 535-540

6 Zhao Q, Lu Y, Chen J. Advanced organic electrode materials for rechargeable sodium-ion batteries. Adv Energy Mater, 2017, 7: 1601792

7 Lee S, Kwon G, Ku K, et al. Recent progress in organic electrodes for Li and Na rechargeable batteries. Adv Mater, 2018, 30: 1704682

$8 \mathrm{Kim}$ J, Kim JH, Ariga K. Redox-active polymers for energy storage nanoarchitectonics. Joule, 2017, 1: 739-768

9 Zhou W, Lv S, Liu X, et al. A directly grown pristine Cu-CAT metal-organic framework as an anode material for high-energy sodium-ion capacitors. Chem Commun, 2019, 55: 11207-11210

10 Batten SR, Champness NR, Chen XM, et al. Coordination polymers, metal-organic frameworks and the need for terminology guidelines. CrystEngComm, 2012, 14: 3001-3004

11 Lee HW, Wang RY, Pasta M, et al. Manganese hexacyanomanganate open framework as a high-capacity positive electrode material for sodium-ion batteries. Nat Commun, 2014, 5: 5280

12 Dong $\mathrm{C}, \mathrm{Xu} \mathrm{L}$. Cobalt- and cadmium-based metal-organic frameworks as high-performance anodes for sodium ion batteries and lithium ion batteries. ACS Appl Mater Interfaces, 2017, 9: 71607168

13 Park J, Lee M, Feng D, et al. Stabilization of hexaaminobenzene in a $2 \mathrm{D}$ conductive metal-organic framework for high power sodium storage. J Am Chem Soc, 2018, 140: 10315-10323

14 You Y, Wu XL, Yin YX, et al. High-quality Prussian blue crystals as superior cathode materials for room-temperature sodium-ion batteries. Energy Environ Sci, 2014, 7: 1643-1647

15 Ren W, Qin M, Zhu Z, et al. Activation of sodium storage sites in Prussian blue analogues via surface etching. Nano Lett, 2017, 17: 4713-4718

16 Wu S, Wang W, Li M, et al. Highly durable organic electrode for sodium-ion batteries via a stabilized $\alpha$-C radical intermediate. Nat Commun, 2016, 7: 13318

17 Kim JK, Kim Y, Park S, et al. Encapsulation of organic active materials in carbon nanotubes for application to high-electrochemical-performance sodium batteries. Energy Environ Sci, 2016, 9: $1264-1269$

18 Wang $\mathrm{H}, \mathrm{Hu} \mathrm{P}$, Yang J, et al. Renewable-juglone-based high-performance sodium-ion batteries. Adv Mater, 2015, 27: 2348-2354

19 Ba D, Li Y, Sun Y, et al. Directly grown nanostructured electrodes for high-power and high-stability alkaline nickel/bismuth batteries. Sci China Mater, 2018, 62: 487-496

20 Jin T, Han Q, Jiao L. Binder-free electrodes for advanced sodiumion batteries. Adv Mater, 2019, 46: 1806304

21 Tan S, Jiang Y, Wei Q, et al. Multidimensional synergistic nanoarchitecture exhibiting highly stable and ultrafast sodium-ion storage. Adv Mater, 2018, 30: 1707122
22 Liu Y, Yang Y, Wang X, et al. Flexible paper-like free-standing electrodes by anchoring ultrafine $\mathrm{SnS}_{2}$ nanocrystals on graphene nanoribbons for high-performance sodium ion batteries. ACS Appl Mater Interfaces, 2017, 9: 15484-15491

23 Gui Q, Ba D, Zhao Z, et al. Synergistic coupling of ether electrolyte and $3 \mathrm{D}$ electrode enables titanates with extraordinary coulombic efficiency and rate performance for sodium-ion capacitors. Small Methods, 2019, 3: 1800371

24 Li C, Yin X, Chen L, et al. Synthesis of cobalt ion-based coordination polymer nanowires and their conversion into porous $\mathrm{Co}_{3} \mathrm{O}_{4}$ nanowires with good lithium storage properties. Chem Eur J, 2010, 16: 5215-5221

25 Gu X, Yan C, Yan L, et al. Carbonates (bicarbonates)/reduced graphene oxide as anode materials for sodium-ion batteries. J Mater Chem A, 2017, 5: 24645-24650

26 Kim SH, Lee HH, Kim JM, et al. Heteromat-framed metal-organic coordination polymer anodes for high-performance lithium-ion batteries. Energy Storage Mater, 2019, 19: 130-136

27 Sharma N, Szunerits S, Boukherroub R, et al. Dual-ligand Fe-metal organic framework based robust high capacity Li ion battery anode and its use in a flexible battery format for electro-thermal heating. ACS Appl Energy Mater, 2019, 2: 4450-4457

28 Li C, Lou X, Shen M, et al. High anodic performance of Co 1,3,5benzenetricarboxylate coordination polymers for Li-ion battery. ACS Appl Mater Interfaces, 2016, 8: 15352-15360

$29 \mathrm{He} \mathrm{H}$, Sun D, Tang Y, et al. Understanding and improving the initial coulombic efficiency of high-capacity anode materials for practical sodium ion batteries. Energy Storage Mater, 2019, 23: 233-251

30 Wang $\mathrm{S}$, Wang $\mathrm{L}$, Zhu Z, et al. All organic sodium-ion batteries with $\mathrm{Na}_{4} \mathrm{C}_{8} \mathrm{H}_{2} \mathrm{O}_{6}$. Angew Chem, 2014, 126: 6002-6006

31 Deng W, Qian J, Cao Y, et al. Graphene-wrapped $\mathrm{Na}_{2} \mathrm{C}_{12} \mathrm{H}_{6} \mathrm{O}_{4}$ nanoflowers as high performance anodes for sodium-ion batteries. Small, 2016, 12: 583-587

$32 \mathrm{Wu} \mathrm{X}, \mathrm{Ma}$ J, Ma Q, et al. A spray drying approach for the synthesis of a $\mathrm{Na}_{2} \mathrm{C}_{6} \mathrm{H}_{2} \mathrm{O}_{4} / \mathrm{CNT}$ nanocomposite anode for sodium-ion batteries. J Mater Chem A, 2015, 3: 13193-13197

33 Zhu $\mathrm{H}$, Yin J, Zhao $\mathrm{X}$, et al. Humic acid as promising organic anodes for lithium/sodium ion batteries. Chem Commun, 2015, 51: $14708-14711$

34 Zhao Q, Gaddam RR, Yang D, et al. Pyromellitic dianhydridebased polyimide anodes for sodium-ion batteries. Electrochim Acta, 2018, 265: 702-708

Acknowledgements This work was supported by the National Natural Science Foundation of China (51772127 and 51772131), Taishan Scholars (ts201712050), Major Program of Shandong Province Natural Science Foundation (ZR2018ZB0317), the Natural Science Doctoral Foundation of Shandong Province (ZR2019BEM038) and the Natural Science Doctoral Foundation of the University of Jinan (XBS1830).

Author contributions Sun Z, Tan K and Hou L performed the experiments; Liu $\mathrm{Y}$ and Yuan $\mathrm{C}$ designed and engineered the samples, and wrote the paper. All authors contributed to the general discussion.

Conflict of interest The authors declare no conflict of interest.

Supplementary information Experimental details and supporting data are available in the online version of the paper. 


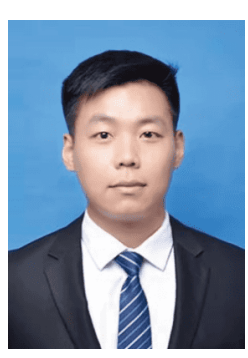

Zehang Sun received a BE degree from LiaoCheng University in 2017. Currently, he is pursuing his MSc degree at the University of Jinan. His research interests focus on the structural design and electrochemical analyses of electrode materials for alkali-ion batteries.

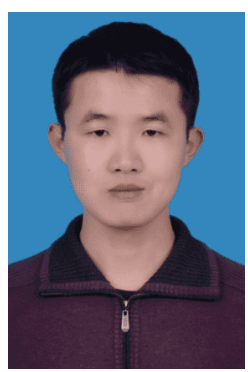

Yang Liu obtained his $\mathrm{PhD}$ degree in chemical technology from Dalian University of Technology in 2017. He then joined the University of Jinan in September 2017. His research focuses on lithium ion batteries and the potential alternative energy storage devices.

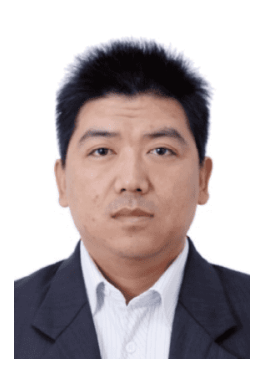

Changzhou Yuan received a PhD from Nanjing University of Aeronautics and Astronautics in 2009. He is a distinguished professor of Taishan Scholar in the School of Materials Science and Engineering, University of Jinan. He is a Highly Cited Researcher (in Materials Science/Crossfield) by Clarivate Analysis from 2016 to 2019, and a Most Cited Chinese Researchers (in materials science) by Elsevier in 2016-2018. His current research focuses on the design and synthesis of micro/nano-materials for electrochemical energy-related applications.

\section{配位聚合物纳米线/还原氧化石墨烯复合柔性薄 膜电极的构筑及储钠性能研究}

孙泽航, 谭可, 侯林瑞, 刘洋", 原长洲*

摘要 构建基于有机材料的高性能柔性储钠电极面临诸多挑战. 本 工作通过可控组装及还原的方式, 实现了铁基配位聚合物纳米线/ 还原氧化石墨烯柔性薄膜的构筑. 多维复合薄膜可直接用作钠离 子电池自支撑负极, 且具有较高的储钠容量 $\left(200 \mathrm{~mA} \mathrm{~g}^{-1}\right.$ 电流密度 下可逆容量为 $319 \mathrm{~mA} \mathrm{~h} \mathrm{~g}^{-1}$ ) 和优异的倍率性能 $\left(3000 \mathrm{~mA} \mathrm{~g}^{-1}\right.$ 大电 流密度下比容量可保持在 $120 \mathrm{~mA} \mathrm{~h} \mathrm{~g}^{-1}$ ). 研究表明有机配体(氨 三乙酸)中的羧基及氨基为储钠活性位点, 而配位金属离子 $\left(\mathrm{Fe}^{2+}\right)$ 不 参与电化学反应. 